\title{
Reflexivity in the Research Process: Psychoanalytic Observations
}

\section{Joanne Brown}

Received 12 November 2003; Accepted 11 fanuary 2005

This paper highlights what psychoanalysis can add to discussions of reflexivity, by specifically describing how reflexivity is conceptualized and fostered on psychoanalytic observation methods courses at the Tavistock Clinic, London. It is demonstrated that this psychological form of reflexivity is relevant to empirical and conceptual work and shown that it shares interesting parallels with debates about reflexivity in social research methods, while also being able to contribute to discussions of what constitutes reflexivity and what kinds of methods course might facilitate it. Reflexivity is often discussed in relation to a researcher's empirical work, but this paper argues that reflexivity is equally needed in relation to the academic context in which most research and learning takes place. This paper demonstrates how psychoanalytic approaches to learning stimulate a reflexive relation to empirical and conceptual work and it provides examples of reflexivity from a two-year infant observation and a research project on romantic love (involving conceptual and biographical research).

\section{Introduction}

In social research, as Finlay (2003a, p. 4) explains, 'myriad forms of reflexivities have been practised', from introspection to critical realism through to deconstructionism. However, she points out that a unifying theme is the 'project of examining how the

\footnotetext{
Dr Joanne Brown is a Lecturer in Mental Health in the School of Nursing and Midwifery at Southampton University. She taught for many years in the Psychosocial Studies subject area at the University of East London (UEL) and on the MA in Psychoanalytic Studies at the Tavistock Clinic, London. Her research interests and publications are informed by a disciplinary approach that combines socio-cultural theory and methods with psychoanalytic theory and methods. She completed a PhD on 'Love and Its Vicissitudes: A Psychosocial Inquiry' at UEL and was trained in psychoanalytic observation methods at the Tavistock Clinic. Her book A Psychosocial Exploration of Love and Intimacy will be published by Palgrave Macmillan in 2006. Correspondence to: Joanne Brown, The University of Southampton, School of Nursing and Midwifery, Mental Health Academic Group, Nightingale Building, Highfield Campus, Southampton SO17 1BJ, UK. Email: J.C.Brown@soton.ac.uk
} 
researcher and inter-subjective elements impact on and transform research'. Finlay (2003b) distinguishes reflection and reflexivity in the following way:

the concepts are perhaps best viewed on a continuum. Reflection can be understood as 'thinking about' something (an object). The process is a more distanced one and takes place after the event. Reflexivity, by contrast, involves a more immediate, continuing, dynamic and subjective self-awareness. (p. 108)

Psychoanalytic methods encourage a 'meditative review of analytic work', ${ }^{1}$ but interestingly, as Gough points out, 'discussions of reflexivity rarely make reference to psychoanalytic theory, despite a long and rich tradition of writing on intersubjective dynamics' (2003, p. 26). This gap in the literature on reflexivity is, however, increasingly addressed by psychosocial ${ }^{2}$ research (e.g. Day Sclater, 1999; Hollway \& Jefferson, 2000a; Hunt, 1989) that does incorporate the concepts and methods of psychoanalysis into its methods of data collection and analysis. This paper will highlight what psychoanalysis can add to discussions of reflexivity, by specifically describing how reflexivity is conceptualized and fostered on psychoanalytic observation methods courses at the Tavistock Clinic, ${ }^{3}$ London.

However, the observational method does not offer a model that can be easily quantified and this raises a question about whether the literature on reflexivity is in danger of being too narrowly focused if it too rigidly calls for procedural guidelines on how to be, as Finlay said, 'subjectively self-aware' (2003b, p. 108). Smythe, for example, points out that: 'reflective practice in nursing is too readily measured by the yardstick of positivism' (2004, p. 326). This can be seen in health and social care, where there are numerous models, steps or cycles to adopt in order to practice and demonstrate reflexivity. It is, of course, invaluable to be given the methodological advice and guidance (as a professional and researcher) that these models offer, but it is also important to consider the idea that you cannot, as one of Smythe's research participants said, 'teach thinking, but you can teach in a way that provokes thinking' (2004, p. 328). Smythe, for example, uses Heidegger to stress the importance of contemplative thinking, and Doanne similarly argues that 'reflexivity as presence is not a methodology with methodological strategies but rather a mode of consciousness' (2003, p. 99). Smythe's and Doanne's approaches to reflexivity share interesting similarities with the conceptualization of reflexivity on observation methods. Observers, for example, do emerge from the course with a method of reflective practice, but it is a method which aims to foster an 'analytic attitude' (M. E. Rustin, 1989, p. 20) and this attitude or sensibility is facilitated by 'learning from the experience of the self in the world' (Waddell, 1988, p. 106) rather than from step-by-step cycles.

Reflexivity is often (and sometimes exclusively) discussed in relation to a researcher's empirical work, but this paper will argue that reflexivity is equally needed in relation to the academic context in which most research and learning takes place. ${ }^{4}$ This paper will, however, ask whether the academic nature of education is sometimes antithetical to the aims of reflexivity. As Proctor, Cutliffe, and Butterworth point out:

In the renaissance of classical learning, Montaigne wrote against the increasingly academic nature of education. He believed it should teach us how to live-be useful in helping us to 
'understand ourselves, ... confront death, quell our wilder ambitions, appease our melancholy or our physical discomforts'. (2001, p. 28)

They quote de Botton (2000), who ironically points out that education instead 'impressed on us the derivation and etymology' of ideas like wisdom or ethics (Proctor et al., 2001, p. 153). This is overstating the case (and the limitations of education), but an important point is being made about the way in which academia may obfuscate an understanding of oneself and of others. Hence, in health and social care, discussions of pedagogy focus on how to integrate practice/experience and theory. ${ }^{5}$

In this paper, a reflexive approach to the identity or profession one inhabits will take the form of a psychology of knowledge or, more accurately, a psychodynamics of theory. ${ }^{6}$ The aim is therefore twofold:

- to discuss how reflexivity is conceptualized in psychoanalytic observation methods and to highlight what it can contribute to discussions of reflexivity in the social sciences;

- to demonstrate how this method stimulates a reflexive relation to empirical and conceptual work.

The first aim of this paper will be achieved by detailing the observation method and pointing to what is distinctive about it in the context of social research methods, and the second aim will be achieved by providing examples of the 'psychodynamics of theory' in the context of a research project on romantic love (involving conceptual and biographical research).

\section{Psychoanalytic Observation Methods}

\section{The Infant Observation Method}

The training in psychoanalytic observation methods (an accredited MA course) entails doing a two-year work-based observation, a two-year infant observation and a oneyear young-child observation (in addition to reading psychoanalytic theory and child/ developmental psychology). The infant observation course in particular is, as M. E. Rustin (1999) points out, mostly used as a pre-clinical course which plays a large part in how students are selected for child psychotherapy training. Although the infant observation method, which is the defining feature of the course, has predominantly been referred to as 'a training in self-awareness' (M. J. Rustin, 1989, p. 68), it is now recognized that observation methods do constitute a training in qualitative research methods (see McFayden, Canham, \& Youell, 1999; Reid, 1997; M. J. Rustin, 1997).

The infant observation work requires the observer to visit a family for one hour each week over a two-year period in order to observe the emotional development of the infant in his/her family setting and observe their own role in this family constellation. It is sometimes argued that infant observations can become a source of explicit support for some mothers. As M. J. Rustin points out:

the most positive aspect of infant observation from the point of view of the families observed seems usually to be that it provides an additional reflective space for the mother 
in particular. The observer provides sympathetic attention to the mother and her baby, without making explicit demands on her, even for information. (1997, p. 97)

Nevertheless, it is the observers who are being given the opportunity to learn from the families observed and who are trusted in a very private realm and this is why the accent is upon them as grateful participant observers (Bick, 1964, p. 559).

As a student on this course I visited one family every week, at the same time, for one hour, for a two-year period. I started my infant observation when 'Toby' was three weeks old, and I finished it when Toby was two. Toby was the second of two children. ${ }^{7}$ Most of the observations consisted of me, Mother and Toby, although in the school holidays, Jamilah (his sister) was also there. Father was present on only a few occasions. The observer's role therefore requires that he or she can approach each observation without—to use Bion's phrase (Bion, 1970)—-memory or desire. This is akin to the phenomenological idea of bracketing out theory and it represents a preference for inductive research. However, it is not characterized by naïve inductivism, because it is recognized that observers project their own perceptual and emotional reality into the settings that they observe. ${ }^{8}$

The observation reports contain extracts of conversations, observations of Toby's movements, or sounds and moods and my emotional responses and impressions. Each visit and report tends to have had its own particular nuance or mood. Some capture the changing seasons or background political events and holidays, birthdays, Christmases etc., all of which affect the tenor and atmosphere of each observation. The reports themselves are raw, largely unstructured, phenomenological accounts of these types of experience. The only structure which is imposed is that the reports try to follow the hour through as chronologically as possible. The reports are presented to a group of five student observers, led by a child psychotherapist, who meet weekly for the duration of their observations.

The following is an extract from an infant observation report, followed by a small sample of the type of commentary that can accompany it:

I arrived at 12.30. No-one answered. I rang again and waited, thinking that Mother would be back from massage class soon. I finally left a note and began to leave, hoping that this wasn't Mothers way of telling that she didn't want me to come anymore. There was a phone over the road and so I rang and Mother answered. Mother explained that the intercom wasn't working and told me to come back over.

She sat with with $\mathrm{T}$ who was either feeding at the breast or asleep. He looked still, and a little limp. He was making heavy breathing sounds, but they were not as loud as last week. Mother said that he still makes the same snorting noises. She picked him up to wind him and he looked very bendy, with his head fallen down and his body curved. His eyes were half-asleep and opening and closing. Mother said that her and Father do want him to be awake in the day. I looked at him and said 'hello T' and he seemed unperturbed, but I did feel as though he had noticed my presence. Mother then put him in the cot and rocked him to sleep. I asked if I could stand where I could see him, Mother said 'Yes, I've got some cards to make'.

I bent down to watch T. At first I could only see one eye and one hand; his eye was moving under its lid and his hand clutched and unclutched. He raised an eyebrow and the stretched skin over his eye seemed delicate. He was in some dreamy state, seeming only half-asleep. 
He moved his body in a stretching gesture, as if he were releasing something. He half moaned to himself and screwed up his eyes, almost as if he were about to fall to sleep, but was fighting it. Something seemed to be missing. He moved his mouth and very briefly fell still, but mostly he stretched and fidgeted. Mother came over and picked him up. She sat down to feed him and said 'Anybody would think that you hadn't been fed'. He made very heavy breathing sounds. (4 weeks old, 2nd visit)

\section{Commentary:}

When I went back to the house after telephoning, the intercom was now working and I wondered if Mother did hear me or not. She, was, however, very reassuring to me and said that she would let me know if she was going to cancel a visit. But my experience was nevertheless an ambivalent one, in which I felt simultaneously rejected and welcomed. Mother was, in fact, initially ambivalent about the observation; she lost my telephone number after our initial interview and on my first visit as I took my first look at Toby asleep in his cot, she said that we 'will try this for 5 weeks'.

The commentary that accompanies a report is usually interpretative and written at the end of the two-year observation. It is then that the infant observation paper is written and it presents themes and patterns that seem to have emerged throughout the observation. The paper offers a narrative that can express and contain the observational experience, but observers only make interpretations after months and years of weekly observation and even then only very tentatively so. Waddell (1988, p. 314) uses Keats' notion of 'negative capability' as a way of expressing the caution that the observer must exercise when linking psychoanalytic interpretations to what has been observed. In Attention and Interpretation, Bion quotes from Keats' explanation of negative capability: 'when a man is capable of being in uncertainties, mysteries, doubts, without any irritable reaching after fact and reason' (1970, p. 125). Waddell (1988, p. 320) argues that the descriptive language used in the observational reports acts as a restraint upon interpretation and she qualifies her own hypotheses about the infant that she observed ('Guila') by stating that Guila cannot ultimately be 'summed up'.

Thoughts about what kind of little baby Toby is or what might be difficult or important for a family thus build up gradually over the passing weeks, months and finally years. An observation is therefore a long sustained meditation on a situation and the observer has to wait for its evolution. ${ }^{10}$ And it is only at the end of this period that observers write their infant observation paper of approximately 5000 words. The seminar leader's comments and those of the group are then collected together and used as a resource. Extracts from infant observation reports are included in the final paper with interpretative commentary and relevant theory. However, it is important to let the observation speak for itself and to ensure that theoretical insights follow the observation rather than squeezing the observation itself into ill-fitting psychoanalytic schemas.

The ethical issues that are involved in observing and writing about infants and their families and one's own capacities to be self-aware are carefully considered throughout psychoanalytic observation training, as one aspect of the preparation for clinical work. The observer has to scrutinize his or her own interactions and intrusions, and inappropriate use of the role, of the group, of theory and so on. For example, on my first visit, Mother asked me what Toby might be dreaming about. I said that he might be 
dreaming about her, or his father or sister. When reporting this in the seminar, the clinician leading the group said that it was inappropriate and although this seems like a mild form of advice/correction, I felt acutely self-conscious for stepping out of the observer role and being potentially intrusive, and I was also being observed by the group as I worked to contain my anxieties at making a mistake-however harmless, in one sense, it was. ${ }^{11}$ This kind of experience was also an occasion to think about my transference feelings in relation to the clinician leading the group (an all-powerful mother/therapist who could see straight through me and expose my shortcomings as a person?), and to the Tavistock (an internationally renowned clinic) and about how I felt being part of a group devoted to understanding the mind and inter-subjective dynamics (in which one's vulnerabilities and/or blind spots could be observed).

The observer cannot be a reserved and forbidding guest, of course, and this was not the point being made. The point was that I needed to discover and learn about this newborn and his relational world and not fall into everyday forms of conversation that preclude attentive and non-interventionist observation. The observer role (rather than that of friend, expert, confidante etc.) is therefore a protection and boundary for observers and families and it is monitored throughout the observations and in the final paper that presents an overall narrative of the observation. ${ }^{12}$

\section{Writerly Practices}

The paper not only represents the development of an observational stance, but also the observer's development of what I would refer to as a 'writerly stance', ${ }^{13}$ which involves scrutinizing the way in which one both observes and writes about observing. Waddell (1988, p. 313) maintains that theories of infant development speak the language of science and refer to the external world, whereas infant observation itself uses a language more akin to poetry, which tries to express the experience of the inner world.

However, the first draft of my observational paper was initially, for example, in danger of being used to corroborate psychoanalytic theory and I think this represented my inability to let go of an academic mode of writing. ${ }^{14}$ Academic writing tends to conform to a 'scientific' model in which one's hypotheses are carefully crafted and tested. What this model of presentation does, of course, is to establish 'rules of theorising' (Craib, 1998, p. 145) which go some way towards protecting a discipline from charges of artistic licence or wild analysis.

However, infant observation papers try to achieve the right balance between poetic or artistic capabilities (imaginative writing) as well as scientific or intellectual capabilities which commit this writing to a 'high standard of literal accuracy and correspondence with observed fact' (M. J. Rustin, 1989, p. 73). ${ }^{15}$ Infant observation papers attempt to integrate theory and experience and the task is therefore to stay 'experience near' (Sandler \& Sandler, 1994, p. 1001) and be vigilant about using literature or making interpretations which are 'experience far'.

Researchers using the terms of psychoanalysis may therefore need to try to achieve an academic style that has affinities with creative writing in order to achieve what Geertz (1988) calls a 'vitality re-phrased' (p. 4). Hunt argues that creative writers need 
to 'delve into the inner world, in order to create writing which, whilst not necessarily autobiographical in the strict sense, is deeply personal' (2002, p. 176). She refers to Seamus Heaney's (1980, p. 43) definition of the writer's voice: 'finding a voice means that you can get your own feeling into words and that your words have the feeling about you in them' (cited in Hunt, 2002, p. 176).

The task that reflexive writing sets us is therefore an internal, emotional task as well as an external academic one. Our work may otherwise be in danger of what Webb (1992) bemoans. In the context of nursing, Webb refers to the 'stilted way in which some students write essays in their attempt to use a neutral, third person format' (p. 747). She says that 'when inexpertly used, this format leads to excruciatingly tortuous sentences about what "the writer" and "the author" think'. This, she says, can produce alienated knowledge, and she therefore warns against the 'objective stance and anonymous, invisible voice' (p. 750).

\section{The Relevance of Observational Methods for Reflexive Social Research Methods}

M. E. Rustin (1989, p. 20) explains that the infant observation method aims to foster an analytic attitude which she defines in the following way:

- the ability to test an hypothesis over time

- a developed sensitivity to emotion

- the capacity for reverie ${ }^{16}$ and the ability to tolerate anxiety, uncertainty, discomfort, helplessness and bombardment.

More specifically, the concepts of transference and counter-transference are introduced as among some of the observer's most important epistemological tools. M. E. Rustin explains that transference refers to the subject's projection of their own inner world into the observational (or any other) setting and counter-transference refers to the 'exploration of those elements in the observer's feeling state which seem to be determined by regular projections from family members' (1989, p. 20) (or from one's research participants, colleagues etc.).

Not all of these characteristics are relevant to social research, but there are some contributions that psychoanalytic observation methods can make to discussions of reflexivity in the social sciences.

For example, although the observation method discourages the premature use of theory, it is nevertheless underpinned by a particular theory of mind and human relations. What is strikingly absent from many accounts of reflexivity is any explicit reference to what theory of mind or relationships is assumed. Psychoanalysis presents a picture of human relations beset by ambivalent feelings of love and hate, and it argues for the importance of recognizing how difficult it is to stay in touch with the multifaceted and subterranean workings of the mind and fluctuating feelings we can have towards others (hence the analytic attitude involves a developed sensitivity to emotion and the capacity to bear discomfort). Understanding oneself and others may be limited if one cannot refer to a theory of mind, affect and relationships that can help to explain why it is difficult to be subjectively self-aware and enter the subjective worlds of others. 
For example, Hollway and Jefferson (2000a), who combine biographical studies with psychoanalytic methods, introduced the notion of the defended interviewer and interviewee in order to incorporate into social research the psychoanalytic contention that anxiety is an a priori affect with which we are born and which can inflect our view of others and the world.

The observation method relies on longitudinal study and it tests one's capacities to hold or contain a relationship over time and observe its dynamics. There may be, for example, occasions when we step out of the observational or biographical stance and disrupt the 'narrative relationship'. ${ }^{17}$ This can happen in observational and biographical work.

There is, of course, an attempt at narrative repair if we do feel that we have lost hold of a narrative relationship. As Plummer (1983) says, the idea of a conversation does not capture the attentiveness and concentration that interviewing (and observing) ideally involves. But if faith in the interview is lost at any point, a platitudinous conversation can ensue and then we have to think about why the narrative relationship was stepped out of and when. Whilst interviewing four people in a residential day centre, I noticed how I moved out of a biographical stance and drifted into conversation. At one point, I asked 'Terry' what his wife looked like. I was shocked to hear this when I played back the tape, because I could not see the relevance of the question and it seemed intrusive. On reflection, I considered how distracting it was to interview people in the centre. Care workers were laughing, joking and peering in the interview room, a buzzer continually went off and a care worker came bounding in unannounced. My work was being undermined and the idea that I wanted to talk to these people about their experiences was not taken seriously. All of the interviewees spoke to me about the death of their spouse and war, and a combination of factors (the playground atmosphere, the interruptions, the thought of death) led to me abruptly stepping out of role. Hence the analytic attitude tries to foster a capacity for tolerating bombardment through longitudinal study in which developmental difficulties (of a very ordinary kind) are likely to be observed.

Another dimension which the observation method prioritizes and which social research could incorporate more of is the non-verbal and unconscious communication which accompanies verbal exchange. What Stern (1985, p. 138) refers to as affect attunement behaviours, for example, occur outside of awareness and do not necessarily lead towards a cognitive empathic knowledge or response: they are for communion rather than communication. Affect attunement, according to Stern, represents one of the ways in which we 'can get inside of other people's subjective experience and let them know we have arrived there, without using words'. The following is an extract from my infant observation following a very tragic death in my family (which I had been informed of the night before, but did not speak of):

Mother led me down to the living room and sat Toby down on his blanket. He smiled at me less shyly than he sometimes did. Mother said he had had his hearing done with Father. Mother passed toys to Toby — a drum with a mirror-and joked about getting the toys the right age for a baby. It was Jamilah's drum. Toby seemed to like a small yellow/green plastic flower and put everything in his mouth. He then reached out his hand to mine and made 
a dance-like, graceful gesture with his arm, like a wave. He reached out for my hand and I put it out to him, he grabbed my fingers and pulled me down to the floor where he sat with Mother. This was the first time he'd ever pulled me down to him, to them. He reached out to me quite a few times and smiled openly. ( $32^{\text {nd }}$ visit, 8 months old)

I cannot know if Toby sensed a quiet and saddened presence in me and responded with this gesture, but he had never reached out for me before and I found it moving and comforting. Irrespective of whether this is an example of a meaningful communication, it is indicative of the way in which an observation focuses on verbal and non-verbal encounters. Observations therefore focus on form (manner, dress, the environment) as well as content (what is said).

In a biographical study of love undertaken by the author (see Brown, 2005), this focus on the non-verbal preceded, in the data analysis, a discussion of the interview. For example, each case description included a section entitled 'First Impressions' which described the room in which the interview took place, where we sat, what it felt like, the atmosphere between interviewer/interviewee.

Following this the form of each interview was discussed, and although this does not focus on non-verbal communication, it is attentive to different functions questions perform, to different modes of speech and to the dynamics of the relationship. For example, I looked at whether my opening question was narrative permitting, ${ }^{18}$ what the interviewee's initial gestalt was in response to this question, ${ }^{19}$ whether I followed an interviews' system of relevancy and what manner of speech was employed by interviewer and interviewee. ${ }^{20}$ I speculated about what states of mind or psychological position a certain manner of speech might express (ambivalence, fatalism). It is also possible to reflect on what different forms of speech can tell us about different decades (for example, are they characterized by action-oriented or feeling-oriented modes of speaking, or narrative versus evaluative modes of speech). As part of thinking about the form the interview took, I reflected on the nature of the narrative relationship and intimacy achieved (if it was), and I looked at how the interview ended.

I therefore prioritized a discussion of the form of the interview before I brought this material into contact with my research questions. This mirrored my attempt to let the actual interview unfold without, in observational terms, a premature use of theory.

As already stated, the analytic attitude involves learning about transference and counter-transference. This could be done by reflecting on one's transference to a clinical supervisor (as, for example, a nurturing and/or punitive mother) or in observation work by thinking about how what you feel is coming from regular projections from the family being visited. However, it is extremely difficult to disentangle the internal from the external (and identify counter-transference) and it may not always be possible to deploy these concepts in social research. It may be easier to focus on one's own projections and transferences, rather than to identify the other's internal dynamics. Hollway and Jefferson (2000a, p. 51), for example, make use of the concepts of transference and counter-transference by explaining how one of Hollway's interviews was permeated by her transference to the interviewee as a daughter figure and there may be many ways in which we can reflect on what kind of internal (pre-historic in Freud's terms) feelings get catalysed in our research. 
It is probably because my interviews were short (one spanned 6 hours, but most were 2 hours) that I did not use psychoanalysis to make interpretations about deep structures of personality (as Hollway \& Jefferson, 2000b, do in the case of 'Tommy'), because I did not feel that my contact with the interviewees or the material itself could justify this. However, it is still possible to apprehend the quality of the relationship or psychic intimacy developed (the wordless communication), and to prioritize a discussion of non-verbal communication (via personal manner and setting). I also used psychoanalytic theory to think about what romance signified for an interviewee (an object of transformation, duplicity, i.e. its seemingly latent meaning) and used the general terms of psychoanalysis to think about the psychological aspects of an interviewee's story or narrative. I asked, for example, what seemed to be their predominant relation to others/the world (trusting, suspicious etc.)? What affects were spoken of more (love, hate, envy, gratitude etc.)? What overall mental attitude or orientation was communicated (concern, paranoia etc.) in the form and content of what was said?

I also speculated about what kinds of material circumstances (age, old people's homes, war, cohabitation, marriage etc.) were conducive to different modes of relating, perceiving, feeling and so on, thus providing a psychosocial analysis of the data. ${ }^{21}$ However, my use of psychoanalysis did not aim to analyse individual Theatres of the Mind (McDougall, 1986). In an observation, something of a young child's or mother's internal world may be communicated over time, but it is only tentatively attended to and, as already stated, the observational emphasis is on self-awareness, thus acting as a restraint on any omnipotent tendencies towards intrusive knowledge.

\section{The Psychology of Knowledge}

\section{Reflexive Learning}

Main (1967) lists the many uses to which ideas or 'mental food' can be put. He says that ideas can create idle mental fat or great energy, can whet the appetite, be treated with contempt, become a useful servant or dominating master, and be a friend or enemy. There is a whole gamut of feeling, he says, from curiosity to loathing, from evangelism to competitiveness, which greets and becomes attached to ideas, and as learners/ researchers we are implicitly being asked by the terms of psychoanalysis to know something of this whole gamut of feeling that we bring to education. As Barfood explains: 'There is no notion in Freud's psychology of a learner with a disinterested curiosity about reality for its own sake' (2002, p. 40).

It is perhaps not surprising then that the observational training described earlier is referred to as training in self-awareness. This self-awareness relates mostly to what kind of observers we become, but it extends to what type of learners we are and to what relationship to knowledge we have.

Following Bion, Waddell (1998) makes a distinction between learning about things and being able to learn from the experience of the self in the world, and it has been my experience that psychoanalytic studies ask us to: 
(1) learn about things, i.e. from the book

(2) learn from the experience of the self in the world

(3) demonstrate this 'binocular vision' in our writing.

However, being committed to this binocular vision in one's academic writing raises the following question:

How do we keep in contact with the activities of our mind (and heart) in the context of academic learning?

Learning from experience and learning by the book are not necessarily mutually exclusive exercises, of course, but it is sometimes questionable what relation to the world or to ourselves we have during periods of intense study. It is perhaps for this reason that Craib (1998, p. 139), a self-confessed lover of ideas, wrote a paper called the 'Psychodynamics of theory'. In it, he describes his ambivalent relationship to intellectual life. He says:

My movement away from theory began when I entered psychotherapy as a patient, and
continued when I later started training as a group psychotherapist. It was indirect: theory
was rarely, if ever, the material of a therapy session, yet as I grew closer to my own life,
theory became less important. Looking back on my life as a student and then as a lecturer,
it now seemed that theory provided me with a way of living that I did not have to own and
an arena for some fairly basic desires and feelings to be acted out. (Craib, 1998, pp. 138-9)

Craib does, however, say that rational thought, i.e. theory, is a way to freedom and that it can give us some control over what is happening internally and externally. Craib mainly criticizes theory that is, in essence, narcissistic and loses contact with the world.

Coming across articles like Craib's, during the course of my work, did make me question the psychodynamics of my own theorizing and look at what Geertz (1988) calls my 'writerly identity' and how integrated this aspect of me was with other parts of my experience and life. I found the sometimes irreconcilable aims of learning from experience and learning by the book particularly difficult to combine in the context of a doctoral research project and thesis entitled 'Love and Its Vicissitudes: A Psychosocial Inquiry' in which I analysed different conceptualizations and ideal-types of love (in sociology, feminism, existentialism, psychoanalysis) and everyday narratives of love. I undertook observation and doctoral studies simultaneously and the different approaches to learning embodied in academia and clinical practice led to the following types of questions as the sometimes irreconcilable tensions between them emerged.

\section{Love Doctor: A Reflexive Approach to Conceptual Work}

At times, I found it problematic to use the insights from psychoanalytic observation methods and psychoanalysis in order to try to qualify as a 'Doctor of Philosophy', let alone a 'Doctor of Love', and I sometimes wondered why I had chosen to study a subject as immodest as love. Bergmann (1987, p. 183) tells us that Freud said that he was wary of raising the 'psychoanalytic flag over the territory of the poets' and that he would not write a 'love life of mankind' until he had overcome his libido. I remember feeling concerned when I read Craib's warning about theory which attempts to be 
expansive and comprehensive (Craib, 1998, p. 142), because I had taken the expansive concept of love as the object of my study. Comprehensive theory can reveal, Craib argues, 'narcissistic omnipotence' (p. 142) and a lack of real intellectual engagement with the world.

What O'Shaughnessy (1994) calls the 'ego's old wish for omnipotence' (p. 942) is surely seduced by research projects and titles which confer on us the status of wisdom and knowledge, and yet the content of observational studies emphasized the importance of a certain kind of modesty and warning about grandiosity. Consequently, one of the main questions that concerned me was how I could write about ideal-typical love (from existentialism, psychoanalysis and sociology) without falsely positioning myself as someone who lived up to these models of authentic, mature and 'pure' ${ }^{22}$ relating.

By writing about love 'authoritatively', for example, did I position myself as someone who knew how to love with integrity, passion and self-composure? Did I implicitly position present myself as someone who would know in rich detail what the secrets of a good relationship are? Did I in any way believe that, by writing about loneliness, jealousy, vanity, the capacity to be alone, to be modest, generous etc., I would traverse the all-important developmental threshold from narcissism to a more honourable concern for others? Or did my very choice of this subject of study reveal my own struggle with how to mitigate jealousy, envy and hate with something less convoluted, messy and shameful?

I often struggled with the problem of how to create a kind of umbilical cord linking knowing about theories of love or psychoanalysis to, or with, my experience of relationships and of psychoanalytic psychotherapy. For example, I asked how I could pay heed to the psychoanalytic injunction to 'know thyself' and not use psychoanalysis as a 'mere intellectual puzzle' (see Bettelheim, 1991). How could I keep the different elements of my experience integrated and grounded, or should I have quite selfconsciously attempted to keep them distinct and separate? And if so, how? Lear, for example, reminds us that in trying to understand human subjectivity, the mind is trying to grasp its own activity' (1990, p. 6). That is, in our research projects, we are partly trying to understand ourselves.

Even the less self-interested aim of understanding others can become fraught with difficulty when one is using psychoanalysis to do so. For example, moments of impasse in my work were sometimes caused by doubts about the ethical dilemmas that I encountered. I stopped interviewing people for a considerable amount of time, because I was worried about asking strangers about their experiences of love and I questioned whether this was, as Waddell (1998) asks of all learning situations, an enlightened desire to understand or intrusive curiosity. Or even worse, did it betray a lack of interest in the other's life and instead represent a necessary expedient for my own professional development?

A concern about intrusion and misuse of people is particularly important in psychoanalytic research, because the interpretive tools used move researchers further into the inside of their subjects than, for example, Geertz (1988) or Squire (2000) may be in favour of. In the context of social research methods, it is understandable that many researchers see it as inappropriate to try to make interpretations about deep structures 
of personality after only limited (or indeed extensive) contact with one's research subjects. It is for this reason that Day Sclater (1999) looks at the psychological effect of assuming certain discursive positions, rather than analysing her interviewee's internal world.

\section{Conclusion}

\section{The Limits of Reflexivity in the Social Research Process}

The danger that accompanies the importation of psychoanalytic concepts into social research is 'wild' or casual analysis of the other's psyche. However, the terms of psychoanalysis emphasize that much of our character (and that of our research participants) is unconscious or wordless. Personal character, for Bollas, is the 'utterance of self through the manner of being, rather than through the representation of mind' (1987, p. 33). He, like Bion, regards the analyst as someone who can introduce a patient to themselves and offer an 'intrasubjective rendezvous'. It is obviously questionable whether we can do psychoanalytic self-reflexive work or psychoanalytic interpretative work without the guidance of an analyst/therapist or outside of the consulting room. However, with important reminders of the limits of reflexivity in the social research process in mind, we can still use psychoanalytic concepts and methods in order to understand our subjects further (in a conceptual and empirical way) and in order to look at the research process and our place within it. However, when using psychoanalysis to understand ourselves and others, it is worth remembering Winnicott's plea to respect that some areas of experience and of the psyche are incommunicado (Winnicott, 1963). Hence although psychoanalysis alerts us to the need for reflexivity in the research process, it also describes the limits to self-knowledge. As Hall comments:

The deceiving nature of the ego usually prevents people from seeing very much further than the version of events which is most pleasing to the ego. It was precisely because of the limits of self-analysis that psychoanalysis was developed. Teaching methods which rely on some 'self-analysis' are likely to prove similarly limited. (2002, p. 26)

This returns us to Smythe's point that thinking cannot be taught, although teaching methods can be used that provoke thinking (Smythe, 2004). It has been the aim of this paper to discuss how thinking of a reflexive kind is provoked in psychoanalytic observational methods courses. This psychological form of reflexivity is relevant to empirical and conceptual work and it shares interesting parallels with debates about reflexivity in social research methods, while also being able to contribute to discussions of what constitutes reflexivity and what kinds of methods course might facilitate it.

Although this paper has focused on reflexivity as a psychological form of thinking, it is recognized that psychosocial forms of reflexivity require sociological and psychological analysis. It is not possible to discuss psychosocial forms of reflexivity in this paper, but in discussing the psychodynamics of theory and pointing to the importance of thinking about the transference relationship one develops in relation to a profession, institution and research project, a critical attitude is demonstrated that has affinities with, and complements, reflexive analyses in the sociology of knowledge. 


\section{Notes}

[1] O’Shaughnessy (1994, p. 942) refers to this quote from W. Bion (UK psychoanalyst) in order to describe her own self-reflexive return to her clinical material.

[2] There are, of course, many forms of psychosocial studies (critical theory, feminism, critical psychology, social constructionism, cultural studies, Lacanian psychoanalysis etc.). The psychosocial studies area which emerged at the University of East London (UEL) (where I lectured from 1992 to 2004) grew out of the undergraduate discipline of sociology, but was to a large part influenced by its close academic links with the Tavistock Clinic, which is predominantly informed by Kleinian/post-Kleinian psychoanalysis. The authors cited above combine Kleinian or object relations psychoanalysis and socio-cultural theory.

[3] The Tavistock Clinic in London (UK) is a National Health Service (NHS) psychoanalytic psychotherapy training/educational institute with a community mental health purpose.

[4] In Finlay and Gough's edited collection on reflexivity (Finlay \& Gough, 2003), a critical (reflexive) approach to a researcher's professional and academic identity is demonstrated by 'ironic deconstruction', which is one form the sociology of knowledge can take.

[5] Many health-related courses prioritize problem-based learning, enquiry-based learning and facilitated learning over more traditional modes of academic learning and teaching.

[6] We are, as Craib (1998) points out, acting out a range of defences when theorizing. That is, our intellectual pursuits are always personal, albeit to varying degrees.

[7] Very little biographical detail will be given in order to protect the confidentiality of the family visited. Pseudonyms have also been used.

[8] This is not a social constructionist/discourse analytic method in which language might be the limit of methodological inquiry. However, language is not seen as transparent either. Bick (1964, p. 565), for example, argues that the fact that 'thinking and observing are almost inseparable' is 'an important lesson, for it teaches caution and reliance on consecutive observations for confirmation' of any hypotheses made. The infant observation method represents a form of critical realism.

[9] This was, of course, a very understandable note of caution.

[10] This method shares similarities with inductive approaches in anthropology and ethnography, although the infant observation method is interested in emotional and psychological development and relationships, rather than in culture (although how the external and internal interact is considered).

[11] Biographical, interpretive, narrative methods (BNIM; see Wengraf, 2001) also use a group (panel) to think through interview data. The group can act as a check on inferences made and offer multiple perspectives and impressions that the solitary researcher lacks.

[12] Social research methods may be less preoccupied with observing boundaries, because they are not pre-clinical trainings. There may also be an objection to the power imbalance that observational boundaries create. Burman, for example, points out that reflexive analysis in feminist research offers a 'sustained focus on power, on the production and use of knowledge and on problematising who has the power to define the interpretation'(1994, p. 138). One of the issues that observers struggle with is whether to give a portfolio of reports to the families observed, because their role is supposed to be non-interventionist. I did give the families I visited a portfolio of reports, because they were, for the most part, descriptive and not intrusively interpretative.

[13] Geertz (1988, p. 9) writes about the problem of signature and the construction of the ethnographer's writerly identity, and Craib (1998, p. 138) writes about our writerly identity through a discussion of the psychodynamics of theory.

[14] Psychoanalytic methods share similar concerns with feminist reflexivity that asks 'how to communicate in terms that engage with and intervene in academic genres without fragmenting, objectifying or disempowering women's experience' (Burman, 1994, p. 131). 
[15] For example, in the final paper all observational extracts are given an exact date, detailing whether this is the 7th or 70th visit to the family. The attention to detail (evidence) required is therefore quite meticulous.

[16] Reverie refers to one's capacity to observe without memory or desire and it is similar to the concept of negative capability.

[17] Duchet argues that 'the production of a real narrative implies that the ... interaction scheme governing the exchange has succeeded in over determining the communication frame of the interview, so that a narrative relationship has been established in which the set of questions and answers refers not to the questionnaire prepared by the historian but to the narrative itself' (1991, p. 91).

[18] The Biographic Narrative Interviewing Method (BNIM) (Wengraf, 2001) was used here to complement the method of psychoanalytic observation. BNIM favours asking narrativeinducing questions in which people avoid abstract theorizing and get closer to giving a detailed description of an event, happening, situation etc.

[19] For example, Terry spoke at length about the Navy, following my question about his experience of romance. In accordance with a non-interventionist, but attentive, stance, I did not interrupt Terry or try to bring him back to my 'system of relevancy'.

[20] BNIM states that there are different modes of speech one can identify-description, argumentation, reports, narration and evaluation. The contention is that argumentation and evaluation may take people away from immediate experience.

[21] Word space does not permit a full discussion of this. See Brown (2005) for a psychosocial discussion of one woman's conceptualization of love.

[22] The pure relationship is Giddens' model of ideal-typical relating (Giddens, 1992).

\section{References}

Barfood, D. (2002). Introduction. In D. Barfood (Ed.), The ship of thought: essays on psychoanalysis and learning (pp. 11-17). London: Karnac.

Bergmann, M. S. (1987). The anatomy of loving. New York: Columbia University Press.

Bettelheim, B. (1991). Freud and man's soul. Harmondsworth: Penguin. [First published in the USA (1983) by Alfred A. Knopf.]

Bick, E. (1964). Notes on infant observation in psychoanalytic training. International Journal of Psycho-Analysis, 4, 558-566.

Bion, W. R. (1970). Attention and interpretation. London: Tavistock.

Bollas, C. (1987). The shadow of the object: psychoanalysis of the unthought known. London: Free Association Books.

de Botton, A. (2000). The Consolations of Philosophy. London: Penguin.

Brown, J. (2005). The compelling nature of romantic love: a psychosocial approach. Psychoanalysis, Culture and Society, 2005, 10, 23-43. New York: Palgrave Macmillan.

Burman, E. (1994). Feminist research. In B. Banister, E. Burman, L. Parker, M. Taylor \& C. Tindall (Eds.), Qualitative methods in psychology: a research guide (pp. 121-141). London: Oxford University Press.

Craib, I. (1998). Experiencing identity. London: Sage.

Day Sclater, S. (1999). Divorce: a psychosocial perspective. Aldershot: Ashgate.

Doanne, G. (2003). Reflexivity as presence: a journey of self-inquiry. In O. Finlay \& B. Gough (Eds.), Reflexivity: a practical guide for researchers in health and social sciences, 93-102. London: Blackwell.

Duchet, C.-M. (1991). Narrative structures, social models and symbolic representation. In S. Gluck \& D. Patai (Eds.), Women's words (pp. 87-98). London: Routledge.

Finlay, L. (2003a). The reflexive journey: mapping multiple routes. In O. Finlay \& B. Gough (Eds.), Reflexivity: a practical guide for researchers in health and social sciences (pp. 3-20). London: Blackwell. 
Finlay, L. (2003b). Through the looking glass: intersubjectivity and hermeneutic reflection. In O. Finlay \& B. Gough (Eds.), Reflexivity: a practical guide for researchers in health and social sciences (pp. 105-119). London: Blackwell.

Finlay, O., \& Gough, B. (2003). Reflexivity: a practical guide for researchers in health and social sciences. London: Blackwell.

Geertz, C. (1988). Works and lives: the anthroplogist as author. Cambridge: Polity Press.

Giddens, A. (1992). The transformation of intimacy. Oxford: Blackwell.

Gough, B. (2003). Deconstructing reflexivity. In O. Finlay \& B. Gough (Eds.), Reflexivity: a practical guide for researchers in health and social sciences (pp. 21-36). London: Blackwell.

Hall, A. (2002). Psychoanalytic research on learning: an appraisal and some suggestions. In D. Barfood (Ed.), The ship of thought: essays on psychoanalysis and learning (pp. 17-41). London: Karnac.

Heaney, S. (1980). Feelings into words. In Preoocupations: selected prose 1968-1978. London: Faber.

Hollway, W., \& Jefferson, T. (2000a). Doing qualitative research differently: free association, narrative and the interview method. London: Sage.

Hollway, W., \& Jefferson, T. (2000b). Narrative, discourse and the unconscious: the case of Tommy. In M. Andrews, S. Day Sclater, C. Squire \& A. Treacher (Eds.), Lines of narrative, pp. 136-149. London: Routledge.

Hunt, C. (2002). Psychological problems of writer identity: towards a Horneyan understanding. In D. Barfood (Ed.), The ship of thought: essays on psychoanalysis and learning, pp. 175-192. London: Karnac.

Hunt, J. (1989). Psychoanalytic aspects of fieldwork. London: Sage.

Lear, J. (1990). Love and its place in nature: a philosophical interpretation of Freudian Psychoanalysis. London: Faber.

Main, T. (1967). Knowledge, learning and freedom from thought. In L. Day \& P. Pringle (Eds.), Reflective enquiry into therapeutic institutions (pp. 1-22). London: Karnac.

McDougall, J. (1986). Theatres of the mind. London: Free Association Books.

McFayden, A., Canham, H. \& Youell, B. (1999). Rating infant observation: is it possible? The International Journal of Infant Observation and its Applications, 2(3), 66-81.

O'Shaughnessy, E. (1994). What is a clinical fact? The International Journal of Psycho-Analysis, 75(5/ 6), 939-949.

Plummer, K. (1983). Documents of life: an introduction to the problems and literature of a humanistic method. London: Allen \& Unwin.

Proctor, B., Cutcliffe, J. R., \& Butterworth, T. (2001). Fundamental themes in clinical supervision. London: Routledge.

Reid, S. (1997). Research developments: introduction. In S. Reid (Ed.), Developments in infant observation, pp. 117-182. London: Routledge.

Rustin, M. E. (1989). Encountering primitive anxieties. In L. Miller, M. E. Rustin, M. J. Rustin \& J. Shuttleworth (Eds.), Closely observed infants, pp. 7-21. London: Duckworth.

Rustin, M. E. (1999). The training of child psychotherapists at the Tavistock Clinic: philosophy and practice. Psychoanalytic Inquiry: A Topical Journal for Mental Health Professionals, 19(2), $125-142$.

Rustin, M. J. (1989). Observing infants: reflections on method. In L. Miller, M. E. Rustin, M. J. Rustin \& J. Shuttleworth (Eds.), Closely observed infants, pp. 52-78. London: Duckworth.

Rustin, M. J. (1997). What do we see in the nursery? Infant observation as laboratory work. The International Journal of Infant Observation and its Applications, 1(1), 93-111.

Sandler, J., \& Sandler, A-M. (1994). Comments on the conceptualisation of clinical facts in psychoanalysis. The International Journal of Psycho-Analysis, 75(5/6), 995-1011.

Smythe, E. A. (2004). Thinking. Nurse Education Today, 24, 326-332.

Squire, C. (2000). Situated selves, the coming-out genre and equivalent citizenship in narratives of HIV. In P. Chamberlayne, J. Bornat \& T. Wengraf (Eds.), The turn to biographical methods in social science: comparative issues and examples (pp. 196-214). London: Routledge. 
Stern, D. N. (1985). The interpersonal world of the infant: a view from psychoanalysis and development psychology. New York: Basic Books.

Waddell, M. (1988). Infantile development: Kleinian and post-Kleinian theory, infant observational practice. The British Journal of Psychotherapy, 4, 313-329.

Waddell, M. (1998). Inside lives: psychoanalysis and the growth of personality. London: Karnac.

Webb, C. (1992). The use of the first person in academic writing: objectivity, language and gatekeeping. Journal of Advanced Nursing, 17, 747-752.

Wengraf, T. (2001). Qualitative research interviewing: semi-structured, biographical and narrative methods. London: Sage.

Winnicott, D. (1965). The maturational processes and the facilitating environment, 1969. London: Hogarth. 